\title{
Tecnologias digitais e a prática docente: Como as metodologias ativas podem transformar a formação de professores
}

\author{
Juliana Silva Arruda ${ }^{1}$, José Aires de Castro Filho ${ }^{2}$, Liliane Maria Ramalho de \\ Castro Siqueira $^{3}$, Rayssa Araújo Hitzschky ${ }^{1}$ \\ ${ }^{1}$ Faculdade de Educação - Universidade Federal do Ceará (UFC) - Centro de \\ Humanidades - Rua Waldery Uchôa, 01 - Benfica. \\ ${ }^{2}$ Instituto UFC Virtual - Universidade Federal do Ceará (UFC) - Campus do Pici - \\ Bloco $901,1^{\circ}$ andar, Fortaleza-CE. \\ ${ }^{3}$ Faculdade de Economia, Administração, Atuária, Secretariado, Contabilidade e \\ Finanças-FEAAC - Av. da Universidade, 2486 - Benfica, Fortaleza - CE. \\ julianarruda24@gmail.com; aires@virtual.ufc.br; \\ ramalholilianelyahoo.com.br; hitzschkyrayssalgmail.com
}

\begin{abstract}
Describes the actions of a training course, which aimed to qualify teachers from various areas for the use of digital resources in light of sustainable themes, relating the practice to active methodologies. The research is descriptive and qualitative. Data were analyzed using Google Drive teacher input and forms. The main results point the interest for the use of new methodologies, essentially the active ones.

Resumo. Descreve as ações de um curso de formação, que teve como objetivo qualificar docentes de áreas diversas para o uso dos recursos digitais à luz de temas sustentáveis, relacionando a prática às metodologias ativas. A pesquisa é descritiva e qualitativa. Os dados foram analisados a partir da participação docente e de formulários do Google Drive. Os principais resultados apontam o interesse para o uso de novas metodologias, essencialmente as ativas.
\end{abstract}

\section{Introdução}

A variedade de tecnologias digitais na sociedade contemporânea tem proporcionado expressivas transformações no processo social, em destaque para a significativa difusão dos recursos móveis de naturezas variadas. Estes recursos influenciam na estruturação da sociedade, dando a ela um novo significado, facilitando a interação e o diálogo. Resta e Laferrière [2007] complementam que a difusão das tecnologias digitais, através do avanço da Internet e dos dispositivos móveis, possibilita a inserção desses recursos nos contextos de aprendizagem, estreitando a relação entre a tecnologia e a educação.

O uso das Tecnologias da Informação e Comunicação (TIC) nos processos de ensino e de aprendizagem pode possibilitar autonomia, renovando a educação e acarretando o desenvolvimento de competências e o compartilhamento do conhecimento, além da experiência com atividades colaborativas [Lima e Maia 2018]. Essa realidade traz um novo cenário para a educação, em especial aos docentes, considerando que as informações da rede, estruturadas através dos recursos tecnológicos, não presentes em ambientes físicos, apresentam informações dinâmicas e com gênese em processos, tais como a interação e a comunicação. Complementa-se, ainda, que o cenário atual é envolto de conhecimentos quase imediatos, devido ao avanço da Internet. Dessa forma, torna-se 
VIII Congresso Brasileiro de Informática na Educação (CBIE 2019)

Anais do XXV Workshop de Informática na Escola (WIE 2019)

necessário incentivar uma análise reflexiva dos conteúdos publicados, objetivando um processamento crítico e não apenas a disseminação indiscriminada.

Os benefícios desse estudo estão centrados em ações reflexivas em torno dos processos de aprendizagem mediados pela tecnologia. A pesquisa originou-se, assim, por meio da seguinte questão: Como as metodologias ativas, envolvendo o uso de recursos digitais e sob à luz de temas sustentáveis, podem favorecer a formação de professores?

A partir dessa problemática, este estudo, fruto de um curso apresentado no III Congresso sobre Tecnologias na Educação - CTRL+e, teve como objetivo geral investigar os reflexos das metodologias ativas com o uso das TIC na formação docente, utilizandose como tema central questões sustentáveis. Como objetivos específicos, propõem-se: 1) Relacionar as metodologias às diferentes áreas de atuação de forma interdisciplinar e 2) Avaliar as possíveis contribuições do curso para a formação docente.

Esta pesquisa, portanto, pretende trazer contribuições para o processo de formação docente, por meio da inserção das metodologias ativas com o uso das TIC como recurso mediador. Além disso, destacam-se os projetos e trabalhos desenvolvidos pelos cursistas.

\section{Metodologias ativas e formação docente como uma interação facilitadora}

A utilização das TIC pode ser um fator de motivação para a constituição do conhecimento e, nesse contexto, elas devem ser consideradas como ferramentas de base pedagógica, as quais podem ocasionar atitudes modernas, ações inovadoras e posturas comunicativas. Sendo assim, as atividades interativas com o uso das tecnologias digitais podem proporcionar a participação ativa na aprendizagem, por meio de trabalhos coletivos.

Os educadores devem, nesse sentido, experimentar ações de uso de novas metodologias, bem como a socialização e o compartilhamento de conhecimentos. Dessa forma, entende-se que estas metodologias podem auxiliar os docentes durante a apresentação de conteúdos teóricos associados às atividades colaborativas, proporcionando-lhes a oportunidade de vivenciar a própria prática e servindo de apoio para que estes se sintam mais seguros. Moran [2013] considera que os objetivos do processo educacional devem estar atrelados às metodologias. O uso das metodologias ativas fornece alternativas para que os educadores, através da sua prática pedagógica, formem alunos com postura crítica e ativa [Coetzee e Schmulian 2012].

A inclusão digital está inserida no cenário social de práticas educativas, portanto, essa deve ser refletida e discutida [Santiago et al. 2016]. Rodrigues et al. [2011] complementam que o planejamento pedagógico na execução das atividades com inclusão das TIC na educação, envolvendo toda a sociedade, deve ser implementado.

Nascimento e Castro-Filho [2015] consideram que a Internet, através dos dispositivos móveis como smartphones, tablets e netbooks, oportunizam variados tipos de recursos que possibilitam a autoria e a criatividade, com a promoção da participação, do compartilhamento e dos diálogos.

\section{Procedimentos metodológicos}

A metodologia tem abordagem de natureza qualitativa, considerando-se que as observações e as estratégias utilizadas pelos sujeitos serão analisadas e interpretadas. As hipóteses da pesquisa surgem no momento em que o estudo se desenvolve, tendo como meta principal a construção do conhecimento e não somente a emissão de opiniões.

O contexto metodológico foi desenvolvido visando a inserção do conhecimento prático das metodologias ativas junto aos inscritos no CTRL+e. O desenvolvimento do 
curso abrangeu desde a introdução da conceituação e tipificação das metodologias ativas até a aplicação empírica desse instrumental com o uso de recursos digitais. O objetivo do curso foi desenvolver metodologias ativas com o uso de recursos digitais junto a professores de áreas diversas. Para tanto, foram propostas vivências voltadas à prática digital e crítica e que, consequentemente, chegassem aos alunos, perpetuando-se por toda sociedade. O conteúdo foi estabelecido a partir de temas envolvendo a Cidadania Planetária e a Consciência Sócio sustentável, em um contexto interdisciplinar.

A amostra envolveu docentes de diversas áreas: Física, Matemática, Enfermagem, Pedagogia, Biologia, Geografia, Fisioterapia, Sociologia, Administração, Informática, Letras e Língua Estrangeira. Essa diversidade possibilitou o desenvolvimento dos temas sobre diferentes olhares, fornecendo o caráter interdisciplinar do curso.

As fases foram desenvolvidas da seguinte forma: 1- Discussão das características docentes contemporâneas e a mudança do contexto educacional através das TIC; 2 Apresentação dos conceitos e tipificação das metodologias ativas; 3- Demonstração de situações reais do uso de metodologias ativas em diferentes áreas; 4- Análise de forma compartilhada, abrangendo o mapeamento de uma disciplina com a utilização de metodologias ativas e recursos digitais, a partir de discussões entre o grupo e as formadoras e 5- Vivência prática e apresentação do planejamento. Nesta fase, foram construídos mecanismos, por meio do planejamento de uma aula com recursos digitais, tais como Google Drive, slides, redes sociais e vídeos. Ao final, os participantes realizaram uma autoavaliação e do curso, por meio de um formulário on-line do Google.

\section{Resultados e Discussões}

A partir da metodologia utilizada e do corpo teórico discutido no desenvolvimento do curso, além dos depoimentos dos participantes e das atividades práticas desenvolvidas em grupo, foi possível perceber que a metodologia adotada, já baseada em metodologias ativas, facilitou o engajamento, a participação e a aprendizagem dos cursistas.

No formulário de sondagem, quando questionados sobre a interdisciplinaridade, TIC e metodologias ativas, $87,5 \%$ acharam que conseguiriam trabalhar com os colegas; 4,5\% revelaram impossibilidade devido a postura educacional; 4,5\% disseram não ter tempo para planejar e 4,5\% argumentaram que o currículo da instituição não permite. Esses dados justificam a necessidade do curso, pois os docentes têm interesse em trabalhar com as novas metodologias e as tecnologias com ajuda dos colegas $(87,5 \%)$.

Os participantes demonstraram interesse em aumentar seus conhecimentos sobre o tema. A metodologia adotada envolveu formulários, elaboração de um plano de aula, com o emprego das metodologias ativas com viés interdisciplinar e transdisciplinar, com o tema sustentabilidade e cidadania planetária. A escolha do tema deu-se pela facilidade de relacionar e utilizar o caráter inter e transdisciplinar dos conteúdos. O desenvolvimento dos planejamentos transcorreu-se de forma colaborativa, por meio da formação de grupos, utilizando recursos digitais, smartphones, notebooks e laptops. Essa metodologia favoreceu o desenvolvimento de práticas e mudanças de posturas, visto que eles construíram seus próprios conhecimentos (Moran 2013).

Dentre os recursos trabalhados, destacam-se músicas internacionais sobre a seca para o estudo de línguas estrangeiras e conteúdos motivadores como charges, reportagens e tirinhas. Vale destacar que todo o material foi produzido por meio de slides e de buscas na Internet. Além disso, os grupos propuseram a elaboração de projetos, o desenvolvimento de cartilhas eletrônicas educativas e, ainda, a produção de brinquedos utilizando a plataforma Pinterest e a elaboração de podcasts e um vlog. 
VIII Congresso Brasileiro de Informática na Educação (CBIE 2019)

Anais do XXV Workshop de Informática na Escola (WIE 2019)

Os projetos apresentados demonstraram um caráter interdisciplinar, abordando o tema cidadania planetária em diversas disciplinas, além de utilizar os recursos tecnológicos no seu desenvolvimento. O grupo 1 utilizou charges e músicas que abordaram a seca, o uso consciente e sustentável da água, abordando o caráter interdisciplinar dos componentes do grupo, formado por profissionais das áreas da saúde, matemática e educação (Figura 1). A metodologia sugerida envolveu diferentes estratégias que os alunos podem vivenciar no dia a dia para práticas sustentáveis.

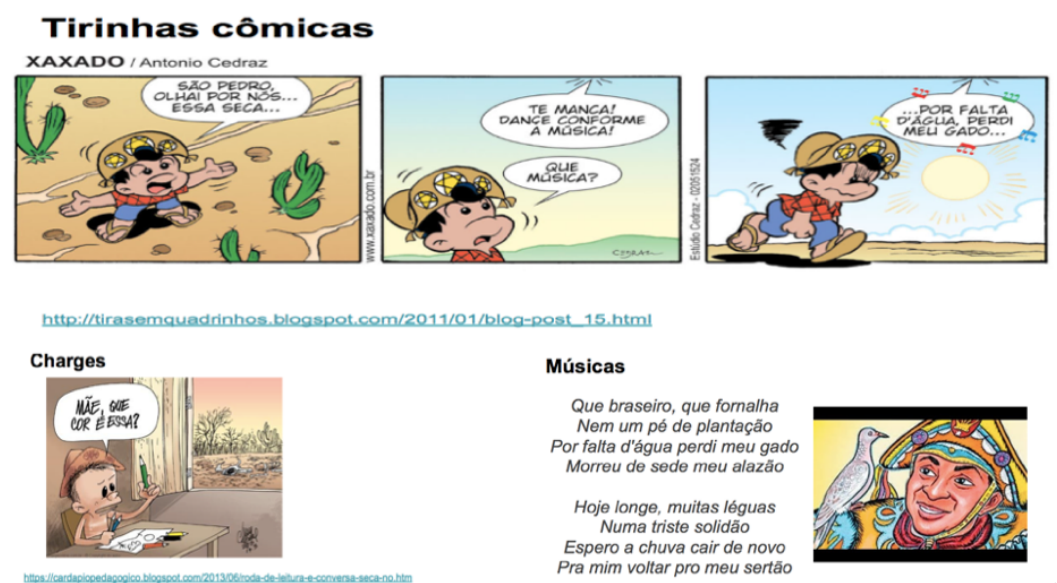

Figura 1. Metodologia do Projeto Grupo 1

Ao final, foi aplicado um formulário de avaliação do curso. A relevância do uso das metodologias ativas ficou evidenciada, visto que $92,3 \%$ dos cursistas avaliaram como positiva a metodologia adotada pelas formadoras, conforme gráfico 1

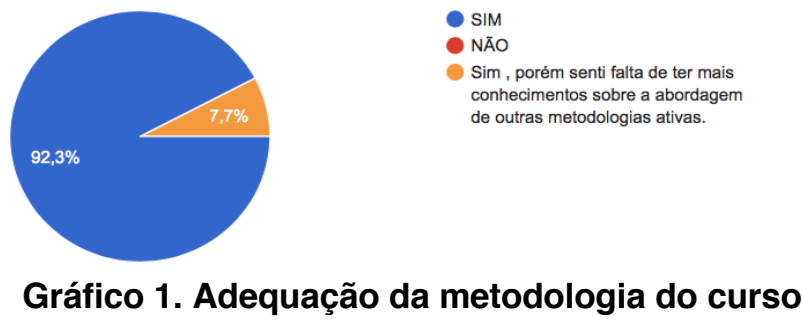

Ainda de acordo com o gráfico 2, a maioria dos cursistas julgou adequada a metodologia adotada e $7,7 \%$ gostariam de um aprofundamento maior em relação aos tipos de metodologias ativas e temas sustentáveis. Sobre os pontos positivos do curso, foram destacados: a relação entre a teoria e a prática; a experiência na área de docência demonstrada pelas proponentes, enriquecendo o momento formativo; a objetividade, clareza e a humildade das facilitadoras; o curso de pequena duração, tendo em vista que foi possível conhecer as metodologias ativas, pondo-as em prática de forma eficaz e, ao mesmo tempo, eficiente. A seguir, tem-se o depoimento de um dos cursistas, o qual este evidencia algumas contribuições do curso:

\section{Depoimento professor A \\ (...) Pudemos conhecer outros participantes e pensar em conjunto sobre como aplicar metodologias ativas usando temas sustentáveis na nossa sala de aula, além de compartilhar o material com os participantes.}

Outras vantagens que os docentes consideraram foram a metodologia, os temas sustentáveis e a interdisciplinaridade. Essa avaliação comprova que os docentes demonstram a necessidade em trabalhar essas temáticas. As metodologias ativas também foram fatores que representaram a urgência na adoção de novas estratégias de ensino no processo educacional. A partir das discussões e dos depoimentos dos cursistas, percebe- 
VIII Congresso Brasileiro de Informática na Educação (CBIE 2019)

Anais do XXV Workshop de Informática na Escola (WIE 2019)

se que o curso atingiu seu objetivo inicial. Além disso, considera-se que as metodologias ativas se configuram um tema de interesse comum no meio docente, no que se refere ao conhecimento acadêmico quanto ao aprofundamento de práticas de ensino.

\section{Considerações Finais}

A partir das vivências dos cursistas, procurou-se relacionar a práxis com base em questões teóricas, objetivando responder à pergunta inicial da pesquisa: Como as metodologias ativas, envolvendo o uso de recursos digitais e sob à luz de temas sustentáveis, podem favorecer a formação de professores?

Os formadores da turma puderam favorecer experiências que possibilitaram maiores interações e práticas dos participantes, por meio de atividades envolvendo vivências sociais sustentáveis em um contexto interdisciplinar. A função exercida pelas proponentes explicitou o papel de mediação crucial do professor, ao ocasionar momentos de reflexão e diálogo junto aos cursistas, promovendo situações desafiadoras e a mudança de postura dos docentes. Percebe-se que estes saíram da posição de expectadores para a de atores, desenvolvendo planos de aulas e dando sugestões de materiais. Esses momentos empíricos possibilitaram o surgimento da autonomia e de um processo mais qualitativo de aprendizagem.

O tema trabalhado, no caso a sustentabilidade, por ser atual e discutido no meio educacional, social e cultural dos professores, também criou esse ambiente propício ao desenvolvimento, visto que foi passível de discussões e de questionamentos.

Para pesquisas futuras, sugere-se a ampliação da pesquisa com outros tipos de metodologias ativas, além da proposta de utilização de aplicativos específicos e outros recursos tecnológicos com outros temas ligados à sustentabilidade, cidadania planetária e responsabilidade social.

\section{Referências}

Coetzee, S. A.; Schmulian, A. (2012) "A critical analysis of the pedagogical approach employed in an introductory course to IFRS". Issues in Accounting Education.

Lima, R. M. S; Maia, D. L (2018) "Revisão de Literatura com Suporte de Revisão Sistemática Sobre a Integração de TDICs no Ensino da Matemática". In: Anais dos Workshops do Congresso Brasileiro de Informática na Educação - CBIE, Ceará.

Moran, J. (2013) "Mudando a educação com metodologias ativas." In: Souza, Carlos Alberto de; Morales, Ofélia Elisa Torres (org.). Coleção Mídias Contemporâneas. Disponível:<http://www2.eca.usp.br/moran/wpcontent/uploads/2013/12/mudando_m oran>.Acesso em: 27 fev. 2018.

Nascimento, K. A. S.; Castro Filho, J. A. (2015) "Aprendizagem móvel e suas tecnologias: uma revisão sistemática da literatura". In: Anais dos Workshops do Congresso Brasileiro de Informática na Educação. CBIE, p. 721.

Resta, P; Laferrière, T. (2007) "Technology in support of collaborative learning". Educational Psychology Review, v. 19, n. 1, p. 65-83.

Rodrigues, N. N. et al. (2011) "Tecnologias de Informação e Comunicação Aplicadas à Terceira Idade". Workshop de Informática na Escola. In: Congresso Brasileiro de Informática na Educação - CBIE, Aracaju.

Santiago, L. B. M. et al. (2016) "O uso das Tecnologias Digitais na busca da superação do analfabetismo”. Workshop Sobre Tecnologias Móveis Na Educação. In: Congresso Brasileiro de Informática na Educação - CBIE, Uberlândia. 